\title{
Research on Distribution Network Security Analysis Based on $K(N-1+k)$ Criterion and Rank Preference Optimal Ordering
}

\author{
Wang Zengping, Yao Yuhai, Yu Junya, and Yun Chentai \\ State Key Laboratory for Alternate Electrical Power System with Renewable Energy Sources, North China Electric Power University, \\ Changping District, Beijing 102206, China
}

Correspondence should be addressed to Yao Yuhai; yao_yuhai@163.com

Received 23 January 2014; Revised 6 May 2014; Accepted 12 May 2014; Published 25 May 2014

Academic Editor: Hongjie Jia

Copyright (c) 2014 Wang Zengping et al. This is an open access article distributed under the Creative Commons Attribution License, which permits unrestricted use, distribution, and reproduction in any medium, provided the original work is properly cited.

The objective of security analysis is to find the weak link of distribution network. The $K(N-1+k)$ criterion based on the characteristics of distribution network was proposed for distribution network security analysis. According to the $K(N-1+k)$ criterion, the electrical devices in the contingency set can be classified into two kinds. The first kind meets the requirement of the $K(N-1+k)$ criterion. The rank preference optimal ordering (RPOO) was proposed to evaluate the damage degree of power system. The second kind does not meet the requirement of the $K(N-1+k)$ criterion, and it is the weak link of distribution network. A numerical experiment shows that the method is efficient and feasible, and the proposed method can provide assistant decision-making for safety precautions.

\section{Introduction}

With the rapid development of distribution management system (DMS), distribution network security analysis (DNSA) is a vital part of DMS and has attracted wide attention [1].

Compared to the study of transmission network security analysis (TNSA), the study of DNSA is still relatively less. Distribution network is designed in closed loop and operated in open loop [2,3]. Transmission network has no limit on operation in open loop $[4,5]$. The TNSA is based on the $N-1$ criterion [6-8]. The essence of the $N-1$ criterion is uninterrupted power supply, when one of electrical devices is fault. There are lots of switches in distribution network for the failure isolation and restoration. When permanent fault occurs in the distribution network, the short-term power off is inevitable in the nonfault and out-of-service areas. In this perspective, the DNSA cannot simply copy the $N-1$ criterion of TNSA.

Traditional DNSA $[9,10]$ only focused on finding out the electrical devices which dissatisfy the requirement of the security analysis criterion. And it is not to evaluate the damage degree caused by the fault of these electrical devices. Once an electrical device is fault, it will bring a harmful effect on power system. DNSA should be to evaluate the damage degree after a fault occurs and to further find out the potential weakness in power grid.

This paper presented the $K(N-1+k)$ criterion for DNSA. According to the $K(N-1+k)$ criterion, the rank preference optimal ordering method (RPOO) was introduced to evaluate damage degree, and it can identify the potential weakness in distribution network.

\section{2. $K(N-1+k)$ Criterion}

Considering the characteristics of the distribution network, study [11] presented the $N-1+1$ criterion for DNSA. The $N$ is the number of electrical equipment in power system. The -1 means that one of electrical devices is fault and isolation. The +1 means that one time of switching operation is needed for supply restoration. However many studies [12-14] illustrate that numbers of switching operation are required for supply restoration. Thus, the $N-1+1$ criterion for DNSA is not fit to the practical engineering.

The analysis of DNSA is based on the given operation mode. It is supposed that the electrical devices are fault one by one. Under the condition of the system operation constraint, the DNSA is to evaluate the safety of distribution network and 
to find out the weaknesses in the system by judging whether power supply can be resumed completely.

The $N-1+k$ criterion is improved based on the $N-$ $1+1$ criterion. When one of the electrical devices is fault and it has been detected and isolated, in order to restore power in the nonfault and out-of-service areas, $k$ times of switching operation are need.

Because of the variable structure characteristic of distribution network, the restoration scheme is not always single but $K$. In the perspective of the security, greater value of $K$ is desired.

Based on the $N-1+k$ criterion, the $K(N-1+k)$ criterion is proposed further. The $K$ is the number of feasible restoration schemes which meet the requirement of the $N-1+k$ criterion.

\section{Evaluation Indexes of DNSA}

The main purpose of DNSA is to discover the potential weakness. According to the $K(N-1+k)$ criterion, the electrical devices in the contingency set can be classified into two kinds. The first kind meets the requirement of the $K(N-1+k)$ criterion. It will cause negative effects on the power system when this kind of the electrical devices is fault. The evaluation of negative effects can find the weakness in the system. The second kind does not meet the requirement of the $K(N-1+k)$ criterion, and it is the weak link in power system. For this kind of the electrical devices, the customers that cannot be served need more attention.

3.1. The Evaluation Indexes for the First Kind. For the devices that meet the requirement of the $K(N-1+k)$ criterion, the evaluation indexes of DNSA are as follows.

The $f_{1}$ is the amount of restorable loads in nonfault and out-of-service areas, and it is proportional to the short-term power failure:

$$
f_{1}=\sum_{i \in A} P_{i}
$$

where $A$ is the collection of restorable nodes and $P_{i}$ is the active power of the $i$ th node.

The $f_{2}$ is the time of switching operation for service restoration and it represents the cost of restoration process:

$$
f_{2}=k
$$

where $k$ is the time of switching operation.

The $f_{3}$ is the load rate and itdescribes the maximum load rate of the electrical device in distribution network:

$$
f_{3}=\max _{i \in B}\left(\frac{I_{i}}{I_{N i}}\right),
$$

where $I_{i}$ is the current at the $i$ th feeder; $I_{N i}$ is the rated current of the $i$ th feeder; $B$ is the collection of feeders.

The $f_{4}$ is the power loss of the power grid:

$$
f_{4}=\sum_{i \in B} P_{i \text { loss }}
$$

where $P_{i \text { loss }}$ is the $i$ th feeder power loss.

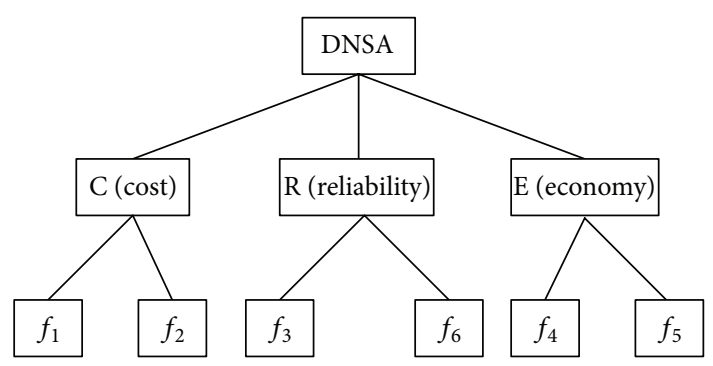

FIGURE 1: The hierarchy model of the first kind.

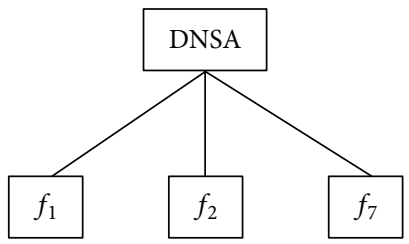

FIGURE 2: The hierarchy model of the second kind.

The $f_{5}$ is the lowest bus voltage in the distribution network after service restoration. For the quality of power supply, the $f_{5}$ should be as high as possible:

$$
f_{5}=\min _{i \in \Omega}\left(V_{i}\right)
$$

where $V_{i}$ is the voltage of the $i$ th bus and $\Omega$ is the collection of the buses.

The $f_{6}$ is the number of the feasible restoration schemes:

$$
f_{6}=K
$$

where $K$ is the number of the feasible restoration schemes.

According to the indexes above, the $f_{1}$ and $f_{2}$ are cost type index, and the $f_{3}, f_{4}, f_{5}$, and $f_{6}$ are benefit type index. The smaller index value of cost type is better, and the larger index value of cost type is better.

The analytic hierarchy process (AHP) [15] is applied to determine the weight of each index. The $f_{1}$ and $f_{2}$ are cost index. The $f_{3}$ and $f_{6}$ are reliability index. The $f_{4}$ and $f_{5}$ are economy index. The hierarchy model is shown as Figure 1.

3.2. The Evaluation Indexes for the Second Kind. For these devices that do not meet the requirement of the $K(N-$ $1+k)$ criterion, the situation of power supply is the main concern. The $f_{1}, f_{2}$, and $f_{7}$ are used to evaluate the security of distribution network, and they are cost type index.

The $f_{7}$ is the amount of unrecovered loads in nonfault and out-of-service areas:

$$
f_{7}=\sum_{i \in A^{\prime}} P_{i}
$$

where $A^{\prime}$ is the collection of unrecovered buses.

The hierarchy model is shown as Figure 2. 


\section{The Evaluation Method for DNSA}

The rank preference optimal ordering method (RPOO) [16] was introduced for DNSA. On the multiobjective decisionmaking method, the RPOO is simple and practical, and it can get the obvious differences among alternatives.

4.1. The Rank Preference Optimal Ordering Method. The $m$ schemes are needed to be evaluated, and each scheme has $n$ evaluation indexes.

The evaluation matrix $R(m \times n)$ is as follows:

$$
R=\left[f_{i j}\right]_{m \times n},
$$

where $f_{i j}$ is the actual value of the $j$ th index related to the $i$ th evaluation scheme.

The index can be divided into two categories, the benefit type and the cost type. The higher the index value of the benefit type is, the better it is. And the cost type is just opposite. The $h$ intervals are formed from the maximum index value to the minimum index value. The $h$ is larger, and the different index value is easier to fall into the different intervals.

The $h$ intervals of the benefit type are divided as follows:

$$
\begin{array}{cc}
1 & {\left[\min _{j}\left\{f_{i j}\right\}, \min _{j}\left\{f_{i j}\right\}+\frac{1}{h} d_{j}\right)} \\
\vdots & \vdots \\
k & {\left[\min _{j}\left\{f_{i j}\right\}+\frac{k-1}{h} d_{j}, \min _{j}\left\{f_{i j}\right\}+\frac{k}{h} d_{j}\right)} \\
\vdots & \vdots \\
n & {\left[\min _{j}\left\{f_{i j}\right\}+\frac{h-1}{h} d_{j}, \max _{j}\left\{f_{i j}\right\}\right] .}
\end{array}
$$

The $h$ intervals of the cost type are divided as follows:

$$
\begin{aligned}
& 1 \quad\left[\min _{j}\left\{f_{i j}\right\}+\frac{h-1}{h} d_{j}, \max _{j}\left\{f_{i j}\right\}\right] \\
& k\left[\min _{j}\left\{f_{i j}\right\}+\frac{k-1}{h} d_{j}, \min _{j}\left\{f_{i j}\right\}+\frac{k}{h} d_{j}\right) \\
& n \quad\left[\min _{j}\left\{f_{i j}\right\}, \min _{j}\left\{f_{i j}\right\}+\frac{1}{h} d_{j}\right) .
\end{aligned}
$$

The $d_{j}$ is defined as follows:

$$
d_{j}=\max _{j}\left\{f_{i j}\right\}-\min _{j}\left\{f_{i j}\right\},
$$

where the $\max _{j}\left\{f_{i j}\right\}$ and $\min _{j}\left\{f_{i j}\right\}$ denote the maximum and minimum value of the $j$ th index related to all schemes. The $d_{j}$ is the difference between the maximum and minimum value of the $j$ th index.

The $G$ is the index rank matrix and is defined as follows:

$$
G=\left[g_{i j}\right]_{m \times n},
$$

where the $g_{i j}$ is the rank value of the $j$ th index related to the $i$ th evaluation scheme.

The index optimal number, $a_{i l j}$, describes the dominant degree which is the comparison of the $j$ th indexrelated to the $i$ th scheme and the $j$ th index related to the $l$ th scheme, and it is defined as follows:

$$
a_{i l j}= \begin{cases}1 & g_{i j}-g_{l j}=h-1 \\ \vdots & \vdots \\ \frac{h-1}{2(h-1)-k} & g_{i j}-g_{l j}=k \\ \vdots & \vdots \\ \frac{h-1}{2(h-1)-1} & g_{i j}-g_{l j}=1 \\ 0.5 & g_{i j}=g_{l j} \\ 0 & \text { other. }\end{cases}
$$

To solve the practical multiobjective decision-making problem, the relative importance of each index needs to be taken into account. The weight of index is as follows:

$$
\sum_{j=1}^{n} w_{j}=1,
$$

where the $w_{j}$ is the weight of the $j$ th index and $w_{j} \in[0,1]$.

The optimal number, $a_{i l}$, describes the dominant degree which is the comparison of the $i$ th scheme and the $l$ th scheme, and it is defined as follows:

$$
a_{i l}= \begin{cases}\sum_{j=1}^{n} w_{j} a_{i l j} & i \neq l, \\ 0 & i=l .\end{cases}
$$

The total optimal number (TON) describes the dominant degree which is the comparison of the $i$ th scheme and the other schemes. Larger TON is better. The TON is defined as follows:

$$
T_{i}=\sum_{l=1}^{m} a_{i l},
$$

where $T_{i}$ is the TON of the $i$ th scheme.

4.2. The Steps of the RPOO. The steps of the RPOO method are shown as follows.

Step 1. Calculate the index values of each scheme, and obtain the evaluation matrix.

Step 2. Determine the weights and the $h$, and get the index rank matrix.

Step 3. According to the index rank matrix, get the index optimal number.

Step 4. According to the index optimal number and the weight, get the optimal number.

Step 5. Calculate the TON of each scheme according to the optimal number. 
4.3. The Steps of the DNSA. The steps of the DNSA are shown as follows.

Step 1. Establish the contingency set, and obtain the weights of the evaluation index based on the AHP.

Step 2. Assume that the electrical devices in the contingency set are fault one by one, and get, respectively, the feasible restoration scheme and the best restoration scheme by the service restoration algorithm [17].

The paper [17] used the nondominated sorting genetic algorithm-II to solve the service restoration. The feasible restoration scheme is the Pareto optimal solution, and the best restoration scheme is got by the preference knowledge described in the paper [17].

Step 3. Calculate the index values of DNSA based on the best restoration scheme and the feasible restoration scheme.

Step 4. According to the $K(N-1+k)$ criterion, the electrical devices in the contingency set are classified into two kinds. The first kind meets the requirement of the $K(N-1+k)$ criterion. The second kind does not meet the requirement of the $K(N-1+k)$ criterion.

Step 5. Evaluate the two kinds of electrical equipment, respectively, by using the RPOO.

\section{Case Studying}

In order to verify the performance of the proposed method, a model [18] as Figure 3 is used. The solid line represents the on state of the switch, and the dashed line represents the off state of the switch. The system holds 16 feeders, and each feeder has switch. Its rated voltage is $23 \mathrm{kV}$. It is assumed that the rated current of each feeder is $700 \mathrm{~A}$. The sum of the loads is $28.7+j 17.3$ MVA. With the operation condition shown in Figure 3, the network loss is $511.44 \mathrm{~kW}$. And the current of feeders is showed as follows: 1-4 (394.13 A), 2-8 (691.61 A), and 3-13 (223.53 A).

It is assumed that the contingency set comprises all 16 feeders. And the $h$ is 100 .

The weight of each index is obtained by the method of AHP. The judgment matrix and the weights of the second kind are shown in Table 1.

The judgment matrixes and the weights of the first kind are shown in Tables 2, 3, 4, 5, and 6 .

It is assumed that the electrical devices in the contingency set are fault one by one, and the restoration algorithm [17] is used to get the corresponding solutions. According to the $K(N-1+k)$ criterion, the electrical devices in the contingency set were classified into two kinds. And the RPOO was introduced to evaluate the damage effect of the two kinds.

Table 7 shows the second kind. This kind does not meet the requirement of the $K(N-1+k)$ criterion. When a fault occurs on 9-12, there are no switches connecting with the nonfault and out-of-service areas, node 12, so the load of node 12 cannot be transformed to other feeders. When one of 4-5, $13-14$, and 2-8 is fault, there is not enough usable amount of

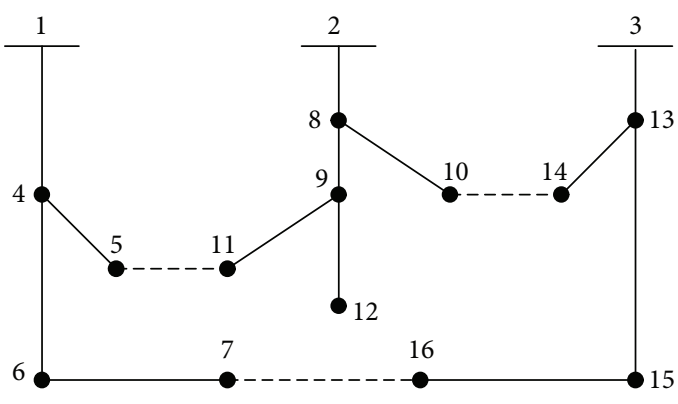

FIGURE 3: IEEE distribution system diagram with 16 feeders.

TABLE 1: Judgment matrix and weight for the security analysis.

\begin{tabular}{lcccc}
\hline Security analysis & $f_{1}$ & $f_{2}$ & $f_{7}$ & Weight \\
\hline$f_{1}$ & 1 & 3 & $1 / 7$ & 0.1549 \\
$f_{2}$ & $1 / 3$ & 1 & $1 / 9$ & 0.0685 \\
$f_{7}$ & 7 & 9 & 1 & 0.7766 \\
\hline
\end{tabular}

TABLE 2: Judgment matrix for the security analysis.

\begin{tabular}{lccc}
\hline Security analysis & $C$ & $E$ & $R$ \\
\hline$C$ & 1 & 3 & $1 / 5$ \\
$E$ & $1 / 3$ & 1 & 3 \\
$R$ & 5 & $1 / 3$ & 1 \\
\hline
\end{tabular}

TABLE 3: Judgment matrix for the cost.

\begin{tabular}{lcc}
\hline Cost & $f_{1}$ & $f_{2}$ \\
\hline$f_{1}$ & 1 & $1 / 3$ \\
$f_{2}$ & 3 & 1 \\
\hline
\end{tabular}

TABLE 4: Judgment matrix for the economy.

\begin{tabular}{lcc}
\hline Economy & $f_{4}$ & $f_{5}$ \\
\hline$f_{4}$ & 1 & 5 \\
$f_{5}$ & $1 / 5$ & 1 \\
\hline
\end{tabular}

TABLE 5: Judgment matrix for the reliability.

\begin{tabular}{lcc}
\hline Reliability & $f_{3}$ & $f_{6}$ \\
\hline$f_{3}$ & 1 & 3 \\
$f_{6}$ & $1 / 3$ & 1 \\
\hline
\end{tabular}

TABLE 6: Weight for the security analysis.

\begin{tabular}{lcccccc}
\hline Index & $f_{1}$ & $f_{2}$ & $f_{3}$ & $f_{4}$ & $f_{5}$ & $f_{6}$ \\
\hline Weight & 0.0748 & 0.2245 & 0.2762 & 0.2772 & 0.0554 & 0.0921 \\
\hline
\end{tabular}

transmission capacity to transform the load of the nonfault and out-of-service areas. So, malfunction of these electrical devices reduces the reliability of power supply and should be taken seriously.

From Table 7 we can see that the fault of 2-8 causes the most negative impacts on the distribution network than the others. When $2-8$ is fault, $9.6 \mathrm{MW}$ loads are power failure 
TABLe 7: The electrical devices of the second kind.

\begin{tabular}{|c|c|c|c|c|c|}
\hline Electrical device & The best restoration scheme & $f_{1} / \mathrm{MW}$ & $f_{2}$ & $f_{7} / \mathrm{MW}$ & TON \\
\hline \multirow{4}{*}{$4-5$} & $4-5$ & \multirow{4}{*}{0} & \multirow{4}{*}{0} & \multirow{4}{*}{3} & \multirow{4}{*}{1.3787} \\
\hline & $5-11$ & & & & \\
\hline & $7-16$ & & & & \\
\hline & $10-14$ & & & & \\
\hline \multirow{4}{*}{$2-8$} & $2-8$ & \multirow{4}{*}{9.6} & \multirow{4}{*}{4} & \multirow{4}{*}{4} & \multirow{4}{*}{0.3883} \\
\hline & $9-12$ & & & & \\
\hline & $8-9$ & & & & \\
\hline & $7-16$ & & & & \\
\hline \multirow{4}{*}{$9-12$} & $5-11$ & \multirow{4}{*}{0} & \multirow{4}{*}{0} & \multirow{4}{*}{4} & \multirow{4}{*}{0.8351} \\
\hline & $7-16$ & & & & \\
\hline & $10-14$ & & & & \\
\hline & $9-12$ & & & & \\
\hline \multirow{4}{*}{$13-14$} & $5-11$ & \multirow{4}{*}{0} & \multirow{4}{*}{0} & \multirow{4}{*}{1} & \multirow{4}{*}{2.5825} \\
\hline & $7-16$ & & & & \\
\hline & $10-14$ & & & & \\
\hline & $13-14$ & & & & \\
\hline
\end{tabular}

TABLE 8: The electrical devices of the first kind.

\begin{tabular}{|c|c|c|c|c|c|c|c|c|}
\hline Electrical device & The best restoration scheme & $f_{1} / \mathrm{MW}$ & $f_{2}$ & $f_{3}$ & $f_{4} / \mathrm{kW}$ & $f_{5}$ & $f_{6}$ & TON \\
\hline & $1-4$ & & & & & & & \\
\hline \multirow[t]{3}{*}{$1-4$} & $5-11$ & 8.5 & 1 & 0.9880 & 945.24 & 0.9348 & 3 & 2.2305 \\
\hline & $10-14$ & & & & & & & \\
\hline & $4-6$ & & & & & & & \\
\hline \multirow[t]{3}{*}{$4-6$} & $5-11$ & 3.5 & 3 & 0.9125 & 551.52 & 0.9714 & 4 & 2.8580 \\
\hline & $8-10$ & & & & & & & \\
\hline & $6-7$ & & & & & & & \\
\hline \multirow[t]{3}{*}{$6-7$} & $5-11$ & 1.5 & 3 & 0.9125 & 497.54 & 0.9714 & 3 & 3.8306 \\
\hline & $8-10$ & & & & & & & \\
\hline & $5-11$ & & & & & & & \\
\hline \multirow[t]{3}{*}{$8-10$} & $8-10$ & 1 & 1 & 0.9125 & 483.86 & 0.9714 & 2 & 5.3212 \\
\hline & $7-16$ & & & & & & & \\
\hline & $4-6$ & & & & & & & \\
\hline \multirow[t]{3}{*}{$8-9$} & 8-9 & 10.1 & 3 & 0.9792 & 703.46 & 0.9578 & 2 & 1.6052 \\
\hline & $10-14$ & & & & & & & \\
\hline & $9-11$ & & & & & & & \\
\hline \multirow[t]{3}{*}{ 9-11 } & $10-14$ & 0.6 & 1 & 0.9574 & 493.15 & 0.9693 & 2 & 4.2470 \\
\hline & $7-16$ & & & & & & & \\
\hline & $9-11$ & & & & & & & \\
\hline \multirow[t]{3}{*}{$3-13$} & $10-14$ & 5.1 & 3 & 0.9574 & 658.84 & 0.9662 & 2 & 2.1315 \\
\hline & $3-13$ & & & & & & & \\
\hline & 5-11 & & & & & & & \\
\hline \multirow[t]{3}{*}{$13-15$} & $8-10$ & 3.1 & 3 & 0.9125 & 539.82 & 0.9714 & 3 & 3.2484 \\
\hline & $13-15$ & & & & & & & \\
\hline & $5-11$ & & & & & & & \\
\hline \multirow[t]{2}{*}{$15-16$} & $8-10$ & 2.1 & 3 & 0.9125 & 508.02 & 0.9714 & 3 & 3.4830 \\
\hline & $15-16$ & & & & & & & \\
\hline
\end{tabular}


temporarily, and $4 \mathrm{MW}$ loads cannot be restored. And the TON of the 2-8 is the smallest. So, the TON can reflect damage degree caused by the malfunction of the electrical devices, and the TON is in inverse proportion to the damage effect of the distribution network.

Table 8 shows the first kind. This kind meets the requirement of the $K(N-1+k)$ criterion.

Form the indexes shown in Table 8, the fault of 8-9 causes the most negative impacts on the distribution network than the others. When $8-10$ is fault, the operation condition is better than the others. And the TON reveals the trend.

The TON can get the obvious differences among alternatives, and it can help engineers to find weak points of the distribution network.

\section{Conclusion}

The $K(N-1+k)$ criterion was proposed for distribution network security analysis, and it is suitable for the radial structure of distribution network. The RPOO was introduced to the multi-index decision-making, and it can get the obvious differences among alternatives. The total optimal number can reflect damage degree caused by the fault of electrical device in the contingency set. The validity and effectiveness of the proposed approach are verified with a numerical example. The proposed approach can point out the weakness of the distribution network and provide guidance for the distribution network transformation and the security defense.

\section{Conflict of Interests}

The authors declare that there is no conflict of interests regarding the publication of this paper.

\section{References}

[1] S. Chakraborty, M. D. Weiss, and M. G. Simões, "Distributed intelligent energy management system for a single-phase highfrequency AC microgrid," IEEE Transactions on Industrial Electronics, vol. 54, no. 1, pp. 97-109, 2007.

[2] S. N. Liew and G. Strbac, "Maximising penetration of wind generation in existing distribution networks," IEE Proceedings: Generation, Transmission and Distribution, vol. 149, no. 3, pp. 256-262, 2002.

[3] P. Siano, P. Chen, Z. Chen, and A. Piccolo, "Evaluating maximum wind energy exploitation in active distribution networks," IET Generation, Transmission and Distribution, vol. 4, no. 5, pp. 598-608, 2010.

[4] D. Shirmohammadi, P. R. Gribik, E. T. K. Law, J. H. Malinowski, and R. E. O'Donnell, "Evaluation of transmission network capacity use for wheeling transactions," IEEE Transactions on Power Systems, vol. 4, no. 4, pp. 1405-1413, 1989.

[5] J. M. Arroyo, N. Alguacil, and M. Carrión, "A risk-based approach for transmission network expansion planning under deliberate outages," IEEE Transactions on Power Systems, vol. 25, no. 3, pp. 1759-1766, 2010.

[6] J. de Silva I, M. J. Rider, R. Romero et al., “Transmission network expansion planning with security constraint," IEE Proceedings on Generation, Transmission and Distribution, vol. 152, no. 6, pp. 828-836, 2005.

[7] K. C. Sou, H. Sandberg, and K. H. Johansson, "Electric power network security analysis via minimum cut relaxation," in Proceedings of the 50th IEEE Conference on Decision and Control and European Control Conference (CDC-ECC '11), pp. 40544059, December 2011.

[8] J. Choi, T. Tran, A. A. El-Keib, R. Thomas, H. Oh, and R. Billinton, "A method for transmission system expansion planning considering probabilistic reliability criteria," IEEE Transactions on Power Systems, vol. 20, no. 3, pp. 1606-1615, 2005.

[9] J. Yu and W. Dong, "Voltage security analysis on the distribution network integrated with wind power using probabilistic load flow," in Proceedings of the International Conference on EProduct E-Service and E-Entertainment (ICEEE '10), pp. 1-4, November 2010.

[10] T. Mander, F. Nabhani, L. Wang, and R. Cheung, "Integrated network security protocol layer for open-access power distribution systems," in Proceedings of the IEEE Power Engineering Society General Meeting (PES '07), IEEE, June 2007.

[11] X. M. Zhang and Z. Z. Guo, "The rule of $k(n-1+1)$ for security analysis of power distribution system," Power System Protection and Control, vol. 29, no. 17, pp. 9-12, 2001 (Chinese).

[12] S. A. Nezam Sarmadi, A. S. Dobakhshari, S. Azizi, and A. M. Ranjbar, "A sectionalizing method in power system restoration based on WAMS," IEEE Transactions on Smart Grid, vol. 2, no. 1, pp. 190-197, 2011.

[13] F. Ren, M. Zhang, D. Soetanto, and X. Su, "Conceptual design of a multi-agent system for interconnected power systems restoration," IEEE Transactions on Power Systems, vol. 27, no. 2, pp. 732-740, 2012.

[14] S. Nourizadeh, M. J. Karimi, A. M. Ranjbar et al., "Power system stability assessment during restoration based on a wide area measurement system," IET Generation, Transmission \& Distribution, vol. 6, no. 11, pp. 1171-1179, 2012.

[15] H. H. Goh and B. C. Kok, "Application of analytic hierarchy process (AHP) in load shedding scheme for electrical power system," in Proceedings of the IEEE 9th Conference on Environment and Electrical Engineering (EEEIC '10), pp. 365-368, May 2010.

[16] C.-F. Chen, C.-X. Zhu, and X.-J. Huang, "Rank preference optimal ordering method in the multi-attribute decision making," System Engineering Theory and Practice, vol. 32, no. 7, pp. 15061516, 2012 (Chinese).

[17] Y. Jiang, J. Jiang, and S. Qiao, "Intelligent service restoration of shipboard power network using nature multiobjective evolutionary algorithm," Proceedings of the Chinese Society of Electrical Engineering, vol. 31, no. 31, pp. 118-124, 2011 (Chinese).

[18] S. Civanlar, J. J. Grainger, H. Yin, and S. S. H. Lee, "Distribution feeder reconfiguration for loss reduction," IEEE Transactions on Power Delivery, vol. 3, no. 3, pp. 1217-1223, 1988. 


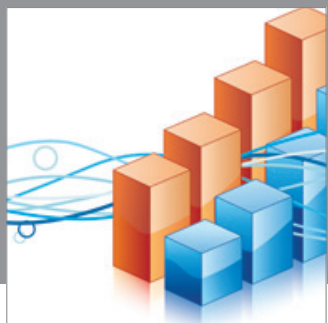

Advances in

Operations Research

mansans

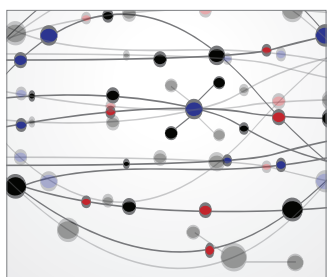

The Scientific World Journal
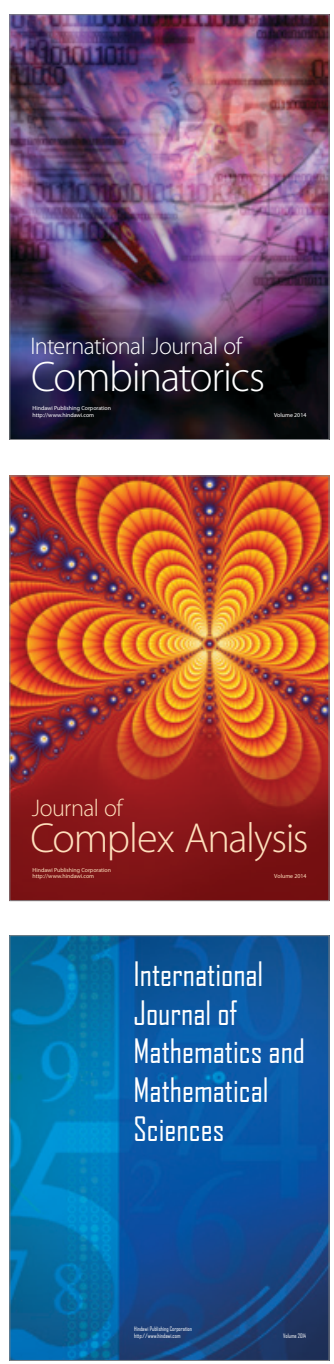
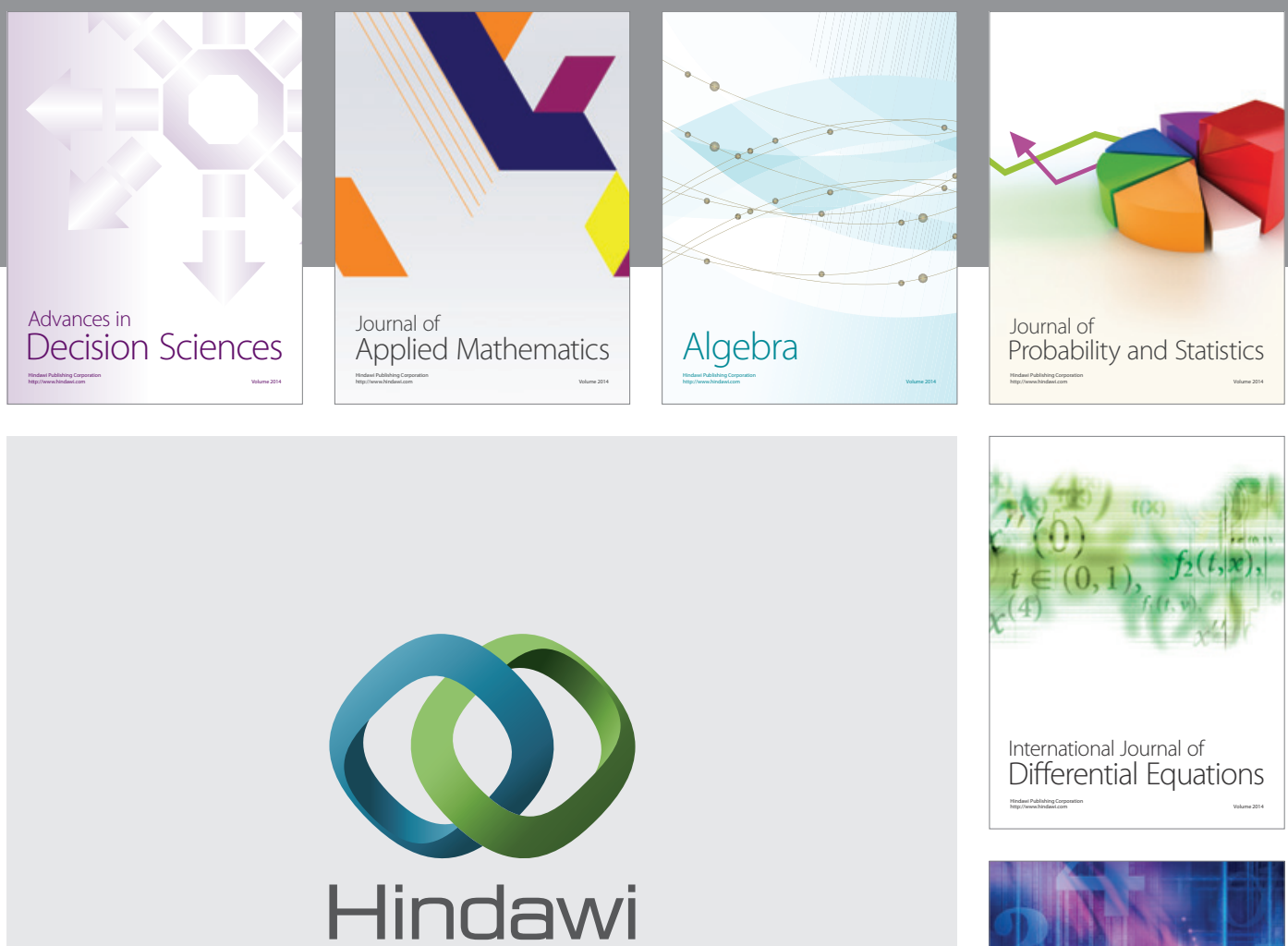

Submit your manuscripts at http://www.hindawi.com
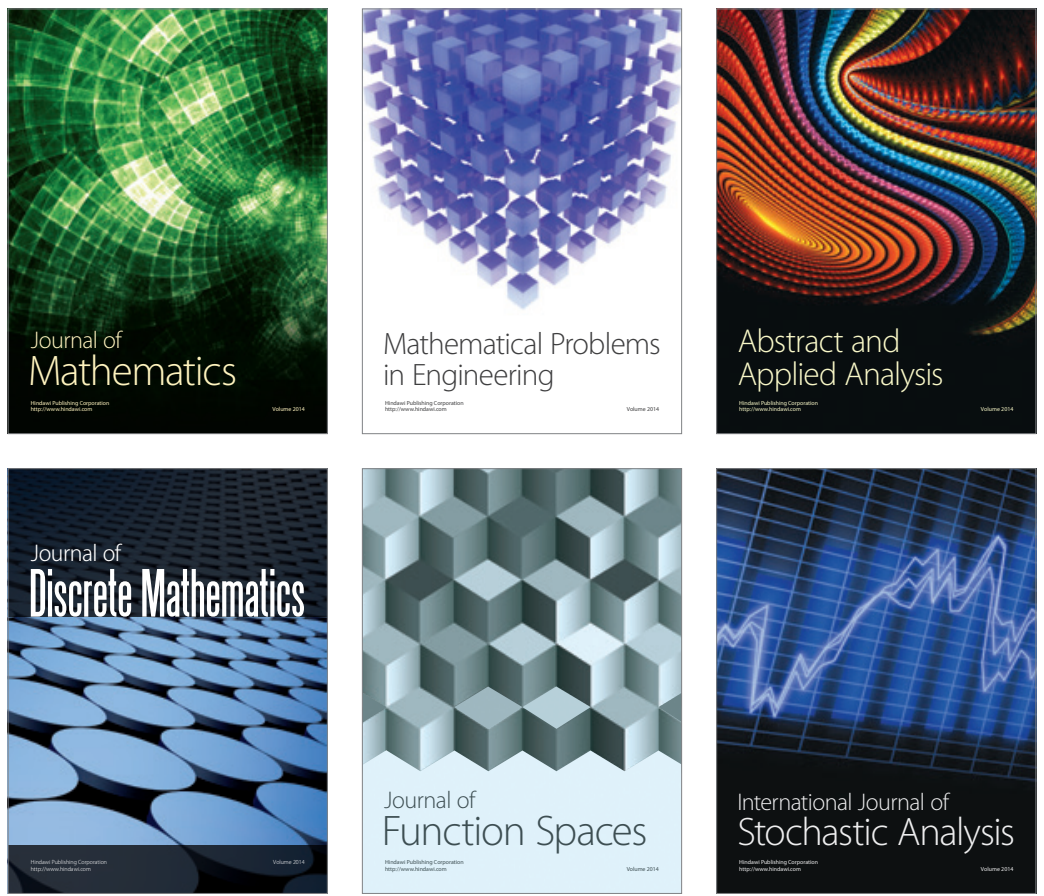

Journal of

Function Spaces

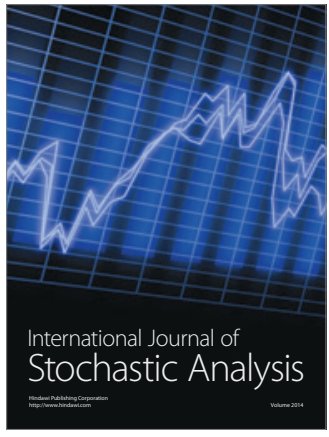

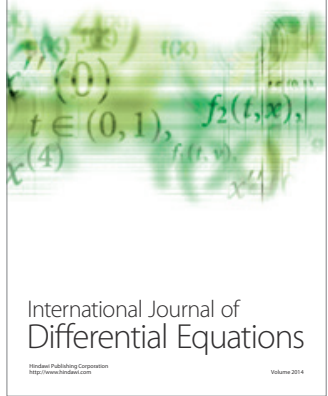
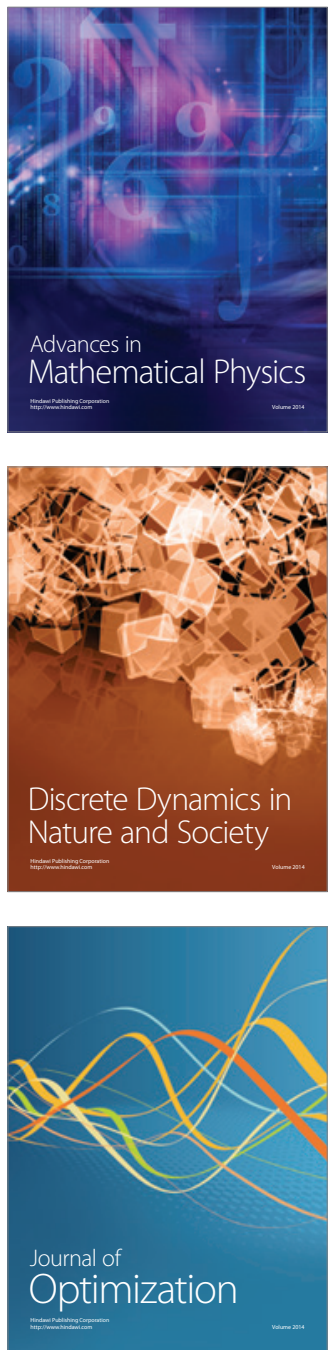